\title{
VARIACIONES MORFODINÁMICAS HIPERANUALES (1951-2007) DE LA LÍNEA COSTERA ENTRE PUNTA DIAMANTE Y RÍO PAPAGAYO, ACAPULCO, MÉXICO
}

\author{
J. E. Bustamante Fernández \\ A. P. Méndez Linares \\ J. R. Hernández Santana \\ Instituto de Geografía. Universidad Nacional Autónoma de México \\ emmanuelgeomex@gmail.com, patyml@igg.unam.mx, santana@igg.unam.mx
}

\section{RESUMEN}

El trabajo presenta el análisis hiperanual (1951-2007) de la dinámica costera de las playas entre Punta Diamante y la desembocadura del Río Papagayo, al oriente del polo turístico de Acapulco, estado de Guerrero, México. Los resultados reflejaron valores extremos de erosión costera de $-72.61 \mathrm{~m}(-6.01 \mathrm{~m} / \mathrm{año})$ y de progradación costera de $+362.76 \mathrm{~m}(+7.84 \mathrm{~m} /$ año), los cuales se validaron con indicadores geomorfológicos y ambientales.

Palabras clave: morfodinámica costera, Acapulco, México.

\section{ABSTRACT}

This paper presents the hyperannual analysis (1951-2007) of coastal dynamics of beaches between Punta Diamante and the mouth of the Papagayo River, to the east of the tourist resort of Acapulco, Guerrero state, Mexico. The results reflected extreme values of coastal

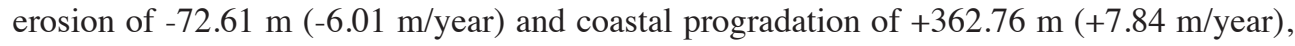
which were validated with geomorphological and environmental indicators.

Keywords: coastal morphodynamics, Acapulco, Mexico.

Fecha de recepción: septiembre 2014.

Fecha de aceptación: febrero 2016. 


\section{INTRODUCCIÓN}

La posición de la zona costera en la convergencia de la interacción dinámica entre la litosfera, la hidrosfera y la atmósfera, la identifican como uno de los espacios más móviles y cambiantes de la geografía global. A esta característica intrínseca a su desarrollo y evolución, se añaden los efectos engendrados por la creciente modificación antrópica, no siempre favorable, enfocada a fines urbanos, portuarios, pesqueros y turísticos, entre las principales actividades socioeconómicas enclavadas en su entorno.

En los últimos decenios, según el IPCC (1997) y Lindeboom (2002), cerca de la mitad de la población mundial habita en zonas costeras y su crecimiento en ellas se ha duplicado con respecto a los montos demográficos nacionales. Por ejemplo, para el caso de Estados Unidos de América, el censo del año 2000 señala que la población costera, incluyendo los condados de los Grandes Lagos, alcanza el 37\% del total nacional (Crowell et al., 2007), mientras que en México 265 municipios de sus 2457 son costeros y 20346955 habitantes radicaban en sus costas en el año 2005 (Azuz-Adeath y Rivera-Arriaga, 2009), es decir, el $18.1 \%$ de la población del país.

Este panorama de ocupación territorial actual y perspectivo en la zona costera, no sólo contribuirá, aun más, a la ruptura acelerada del frágil equilibrio de estos sistemas naturales, sino que inducirá el incremento, ya preocupante, de la vulnerabilidad física y social ante el ascenso sostenido del nivel medio del mar. Por otra parte, dichas condiciones propiciarán el embate más frecuente e intenso de fenómenos hidrometeorológicos extremos, como huracanes, tormentas extratropicales, mareas de surgencia y oleajes de tempestad, entre los más recurrentes.

Este último escenario está introduciendo actualmente una «cultura de indemnización», necesaria y casi permanente, que lamentablemente corroe de manera significativa al producto interno bruto de las naciones, sobre todo de aquellas economías emergentes, cuando realmente la solución descansa en un nuevo reordenamiento y manejo integrado de los territorios, como respuesta adaptativa a los nefastos cambios, ya palpables, en el sistema costero.

La presencia en las costas mexicanas de innumerables huracanes, como Beulah (1967), Gilberto (1988), Roxanne (1995), Paulina (1997), Wilma (2005), Dean (2007), Manuel e Ingrid (2013), han ocasionados centenares de víctimas y miles de millones de dólares de daños materiales, los que han sido resarcidos parcialmente con el presupuesto del Fondo de Desastres Naturales (FONDEN), un verdadero desgaste de la economía mexicana.

En la actualidad internacional, el análisis de los cambios en los ambientes costeros está enfocado a diversas problemáticas, como al cambio climático y a las tendencias del nivel del mar y sus efectos (IPCC, 2013); a la evaluación de la variabilidad costera ante dichos cambios (Morton et al., 2005); a la estimación de la peligrosidad costera ante diferentes fenómenos naturales (Froede, 2006; Márquez et al., 2010); al desarrollo de índices de vulnerabilidad costera (Boruff et al., 2005; Thomas-Bohórquez, 2013); a la regeneración de playas (Hernández y Reyes, 2002); al manejo costero municipal (Moreno et al., 2005); a los cambios morfodinámicos nacionales (Juanes-Martí, 1996), regionales y locales; y al manejo integrado de la zona costera (Barragán, 2003); entre las principales direcciones científicas. 
En México, las investigaciones morfodinámicas costeras no son muy numerosas, pero diversos autores se han enfocado en la dinámica sedimentaria y de la línea costera, y al cálculo de las variaciones morfodinámicas de las costas del Golfo de México y del Pacífico (Ortiz y Méndez, 2000; Hernández-Santana et al., 2008).

El objetivo cardinal del presente trabajo está dirigido al análisis de las variaciones morfodinámicas de las playas localizadas entre Punta Diamante y la desembocadura del Río Papagayo, en el Pacífico mexicano, pertenecientes además a la región oriental del municipio turístico de Acapulco; éstas fueron analizadas con materiales aerofotográficos y cartográficos comprendidos entre los años 1951 y 2007. Para ello, se investigaron las condiciones morfológicas actuales de las playas y sus comportamientos históricos durante estos 56 años, así como las situaciones ambiental y socioeconómica, como factor de modificación antrópica del litoral.

\section{II. ÁREA DE ESTUDIO}

\section{II.1. Localización geográfica}

La zona costera estudiada está comprendida entre los $16^{\circ} 41^{\prime} 03^{\prime \prime}$ y los $16^{\circ} 47^{\prime} 26^{\prime \prime}$ de latitud norte, y los $99^{\circ} 36^{\prime} 33^{\prime \prime}$ y los $99^{\circ} 49^{\prime} 32^{\prime}$, de longitud oeste (Fig. 1), entre Punta Diamante, al norte-noroeste, y la desembocadura del Río Papagayo, al sur-sureste. Se presenta como una costa de acumulativa de $26 \mathrm{~km}$ de longitud, localizada en el oriente del municipio de Acapulco.

\section{II.2. Características naturales}

Desde el punto de vista geológico está constituida por gneises y esquistos, cortados por granitos y granodioritas (Consejo de Recursos Minerales, 1999), con sobreposición de depósitos cuaternarios. Las condiciones geomorfológicas están expresadas en una serie de llanuras acumulativas planas, de carácter poligenético, todas antropizadas por asentamientos humanos, complejos turísticos y parcelas agrícolas.

El clima es cálido subhúmedo de baja humedad, con régimen pluviométrico de verano y precipitaciones medias anuales de $2033.2 \mathrm{~mm}$ (García, 2004), y vientos dominantes del oeste y norte, con velocidades promedio menores a los $10 \mathrm{~m} / \mathrm{seg}$. La principal cuenca hidrológica es la del Río Papagayo, principal fuente sedimentaria de las playas locales, con una superficie de 7 $410 \mathrm{~km}^{2}$ y un escurrimiento medio anual de $3926907.1 \mathrm{~m}^{3}$ (SEPLAP, 1985; CONAGUA, 2011).

Esta zona costera se distingue por un oleaje de alta energía, del orden de 2 a 3 m y con períodos de longitud de onda, que varían entre los 12 y 15 segundos (Flamand, 1991); el tipo de marea es mixta semidiurna, con un rango de diferencia menor a 2 m (SMN, 2013); y las corrientes dominantes con una dirección NW, alcanzan velocidades de hasta $0.5 \mathrm{~m} / \mathrm{s}$ (Pacheco, 1991; Vázquez et al., 1998).

\section{II.3. Desarrollo socioeconómico}

Las características demográficas del municipio acapulqueño han denotado cambios significativos desde la segunda mitad del siglo XX, como resultado de la evolución turística. La 
cabecera municipal, localizada en la costa, es la que ha presentado un mayor dinamismo en comparación con otras localidades, debido a que posee cerca del $85 \%$ de la población total del municipio, con 789,971 habitantes (INEGI, 2011).

De ellos, el $51.6 \%$ se encuentran en condiciones de pobreza, debido al aumento exponencial de la población y a los desplazamientos migratorios campo-ciudad, que provocaron un déficit de la oferta de empleos, principalmente en el sector turístico, que fue el principal factor de atracción. En la actualidad, el INEGI (2011) indica que el total de la población económicamente activa es de 323.429 habitantes, de los cuales el 55.2\% se encuentra en el sector turístico, ya sea por medio de los servicios hoteleros, de transporte o de algún otro tipo vinculado.

Por otra parte, INEGI (2011) reconoce a los sectores primario y terciario, como los más importantes de la economía de Acapulco. El primero abarca 42.185 ha dedicadas a la agricultura, principalmente a cultivos de melón, sorgo forrajero, maíz grano, sandía, jitomate, frijol, sorgo grano, jamaica, tomate verde, calabaza, mango, limón, plátano, café cereza y el cocotero; mientras el sector terciario se vincula primordialmente a la actividad turística.

En el año 2010, los servicios de hospedaje registraron a 245 hoteles, que albergaron a 4.890 456 turistas, de los cuales el $97 \%$ eran residentes en el país y el resto provenía del extranjero; posicionándose como el segundo destino turístico más visitado de México (INEGI, 2011).

\section{Figura 1}

ÁREADE ESTUDIO

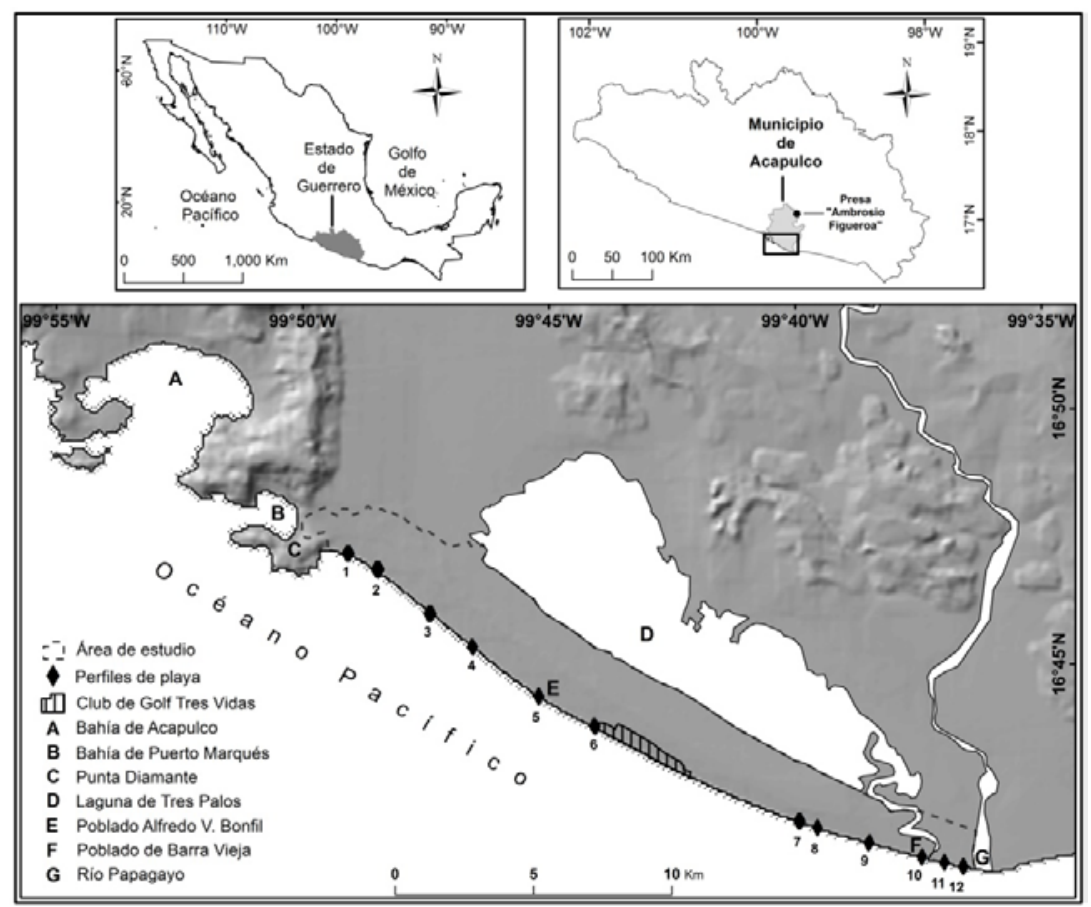

Fuente: elaboración propia. 


\section{MATERIALES Y MÉTODOS}

En los estudios morfodinámicos costeros existen diferentes metodologías, basadas en el empleo de indicadores bióticos y abióticos, que deben seleccionarse adecuadamente, de acuerdo con la escala espacial y temporal de la investigación. A su vez, la selección de indicadores geomorfológicos debe permitir exactitud, bajo costo y significado académico o práctico, siempre evadiendo niveles de incertidumbre que conduzcan a evaluaciones erróneas. Los atributos morfológico-morfométricos del relieve y ambientales de las playas, así como la evaluación multitemporal de la dinámica de la línea de costa, fueron algunos de los indicadores más viables en este trabajo.

El enfoque metodológico contempló tres fases (Fig. 2): I, de clasificación morfogenética del relieve costero; II, de reconocimiento de las tendencias históricas, mediante el análisis multitemporal de la línea costera; y III, de reconocimiento y caracterización de las condiciones actuales de las playas.

Figura 2

ESQUEMA METODOLÓGICO
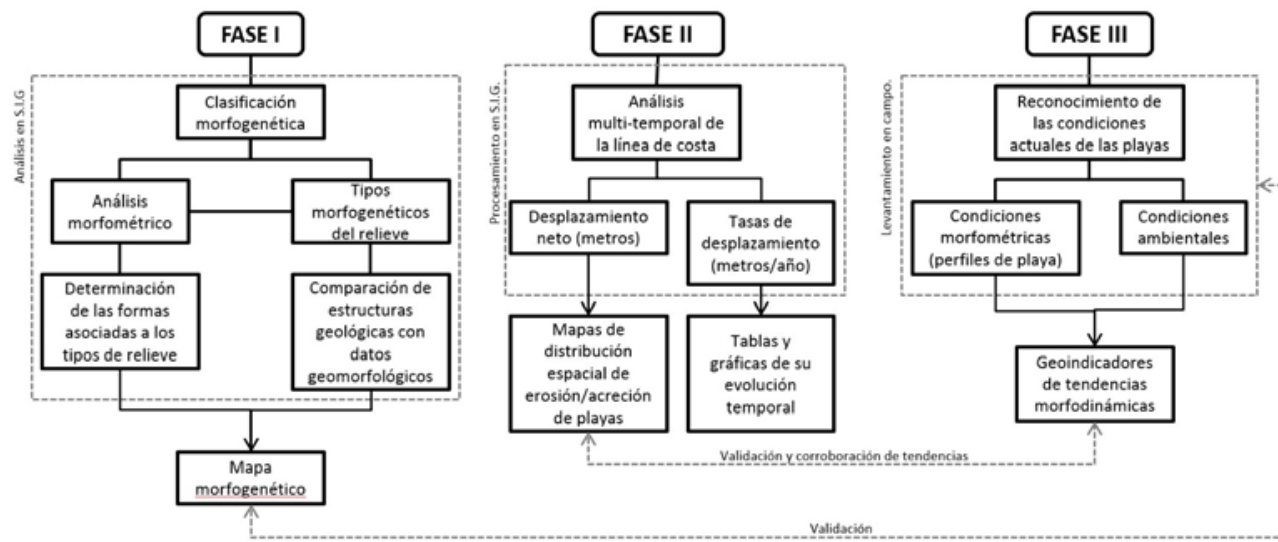

Fuente: elaboración propia.

\section{III.1. Materiales cartográficos, aerofotográficos y digitales}

Para la primera fase, de clasificación morfogenética, se emplearon los Modelos Digitales del Terreno derivados de datos LiDAR (INEGI, 2008), a una resolución espacial de $5 \mathrm{~m}$ y vertical de $1 \mathrm{~m}$. Así mismo, se consultó la carta geológico-minera a escala 1:250,000, de la hoja cartográfica Acapulco (Servicio Geológico Mexicano, 2000).

Los materiales aerofotográficos y cartográficos utilizados para la obtención histórica de la línea de costa fueron las fotografías aéreas, a escala 1:30 000, con resolución del pixel de 10 m (ICA, 1951); las ortofotos, a escala 1:20 000, con resolución de 2 m (INEGI, 1995); y las ortofotos, a escala 1:10 000, con resolución de 1 m (INEGI, 2007). 


\section{III.2. Clasificación morfogenética del relieve costero: Fase I}

A fin de tener un marco geomorfológico de la zona estudiada y entender el contexto de evolución a una escala temporal más amplia, se realizó el análisis morfogenético del relieve costero. Para dicho análisis fueron considerados los criterios metodológicos para el levantamiento geomorfológico detallado, desarrollado por Hernández-Santana et al. (2015) en las zonas costeras del estado de Veracruz, tales como: (1) Interpretación morfométrica del relieve; (2) Análisis de los tipos morfogenéticos del relieve; (3) Comparación de los datos geomorfológicos con la constitución y estructura geológicas; (4) Análisis de los sistemas de llanuras, sus terrazas y fragmentos, y sus formas; (5) Revisión bibliográfica y cartográfica; (6) Método investigativo de campo.

Las investigaciones de campo contemplaron recorridos y muestreo en las estaciones No. 1 a la 12, desde Punta Diamante hasta la desembocadura del Río Papagayo, donde se ejecutaron múltiples transectos transversales y se analizaron las características morfométricas de las formas del relieve, así como las ambientales locales.

\section{III.3. Métodos computacionales en la evaluación de la morfodinámica costera: Fase II}

Las tasas de cambio morfodinámico de la línea costera se generaron, a partir del empleo de la extensión Digital Shoreline Analysis System verión 3.0 (D.S.A.S.) montada en el software ArcGis v. 9.3 (Thieler, 2005), extensión que permite automatizar el proceso de cálculo de dichas tasas.

Tras la identificación y caracterización de las playas, se optó por el trazado de la línea de costa sobre la línea divisoria entre la arena seca y la húmeda. La selección de este rasgo está justificada por las condiciones actuales de la zona, ya que los atributos naturales se encuentran severamente modificados por infraestructura turística, como ausencia de vegetación natural y de dunas en extensos segmentos de playa, así mismo el grado de turbidez del agua no favorece el establecimiento de algún otro rasgo más consistente que la línea de divisoria entre la arena seca y la húmeda. Además, se consideró pertinente esta selección, debido a que el rango de marea es menor a $2 \mathrm{~m}$ y las tonalidades de la arena permitieron, de manera adecuada, discriminar este rasgo en las fotografías aéreas.

Sin embargo, se vuelve necesario reconocer que la incertidumbre asociada a su localización «exacta» es bastante alta debido a su gran dinamismo, por lo tanto, se sugiere establecer un valor de error (o incertidumbre) que esté ligado a una serie de parámetros asociados, tanto a las condiciones naturales de la costa como a los insumos cartográficos empleados (Ruggiero et al., 2013).

El cálculo de las tasas de erosión o de progradación de la costa se obtuvo con el método de la tasa de punto final (End Point Rate - EPR, por sus siglas en inglés), a fin de obtener una tasa promedio anual. El método EPR consiste en obtener de manera lineal, las tendencias erosiva o progradante costeras en un período de tiempo y en un par de líneas de costa. Se calcula dividiendo la distancia (en metros) que existe entre las dos línea de costa temporales entre el número de años transcurridos entre la línea más antigua y la más reciente.

Por otra parte, se obtuvieron las tasas en transectos espaciados cada 10 metros, con la finalidad de obtener de manera detallada las tendencias locales. El criterio de selección 
está ligado a un factor muy particular de esta zona, ya que no todos los segmentos de playa cuentan con las mismas tendencias, debido a las acciones que ejercen los propietarios de los hoteles o los habitantes de los poblados, al acelerar la erosión de sus playas o implementar medidas de retroalimentación por iniciativa propia.

Finalmente, la digitalización de la línea de costa se generó a una escala fija, a fin de evitar ambigüedades en cuanto al detalle o generalización de la misma. En este sentido, se eligió como escala fija 1:10 000 por ser la mejor escala de los insumos aerofotográficos.

\section{III.4. Levantamiento en campo de las condiciones ambientales y morfométricas de las playas: Fase III}

Las estaciones de mediciones instrumentales de los perfiles morfológicos-morfométricos transversales de las playas fueron determinados inicialmente de manera equidistante, pero la inaccesibilidad de algunas zonas por la tenencia privada de los predios, forzó a que las estaciones se realizaran en sitios con acceso directo a la playa.

Los perfiles contemplaron el cálculo de desniveles, los ángulos de inclinación de las superficies y las distancias entre los diferentes morfoelementos de la playa, empleando un clinómetro SUUNTO TANDEM, una cinta métrica de $50 \mathrm{~m}$, un estadal y un equipo Garmin, modelo GPS III+, con precisión de 5 m. Además, se evaluó el estado actual de las dunas en cada estación instrumental.

Los criterios establecidos para fijar los límites extremos de la playa fueron la línea de pleamares, como límite inferior, y la corona de la duna o hasta las construcciones inmediatas a las playas, como límite superior. A su vez, en cada estación fueron evaluadas las condiciones ambientales para conocer el grado de influencia antrópica y sus modificaciones en las playas.

\section{RESULTADOS Y DISCUSIÓN}

\section{IV.1. Morfogénesis del relieve costero}

Los principios teóricos para la clasificación morfogenética contemplaron las categorías básicas del relieve, determinadas por las diferencias en la intensidad de los movimientos neotectónicos (N-Q), expresadas en escalones de lomeríos y sistemas de llanuras; así como el piso altitudinal de las subcategorías del relieve (lomeríos medianos, con $\mathrm{H}$-altitud, menor de $140 \mathrm{~m}$; las llanuras costeras medianas, menores de $20 \mathrm{~m}$; y las bajas y muy bajas, menores a $4 \mathrm{~m}$ ). Los tipos morfogenéticos se establecieron de acuerdo con su morfología, morfometría y el proceso genético de formación, con indicaciones sobre su constitución geológica, incluyendo su datación relativa (Fig. 3).

El relieve acumulativo de la zona costera es bajo y poligenético (marino, eólico-marino y lacuno-palustre, localmente fluvial en la desembocadura del río Papagayo), cerrando por el suroeste a la laguna de los Tres Palos, cuyo espacio en tiempos pleistocénicos y quizás holocénicos tempranos estuvo ocupado por un amplio golfo. A los efectos del presente análisis morfodinámico sobresalen las llanuras marinas acumulativas bajas y muy bajas, y las llanuras eólico-marinas onduladas y planas, ambas inferiores a $4 \mathrm{~m}$ de altitud, en las cuales fueron trazados los perfiles morfométricos (Fig. 4). 
Figura 3

TIPOS MORFOGENÉTICOS DEL RELIEVE COSTERO

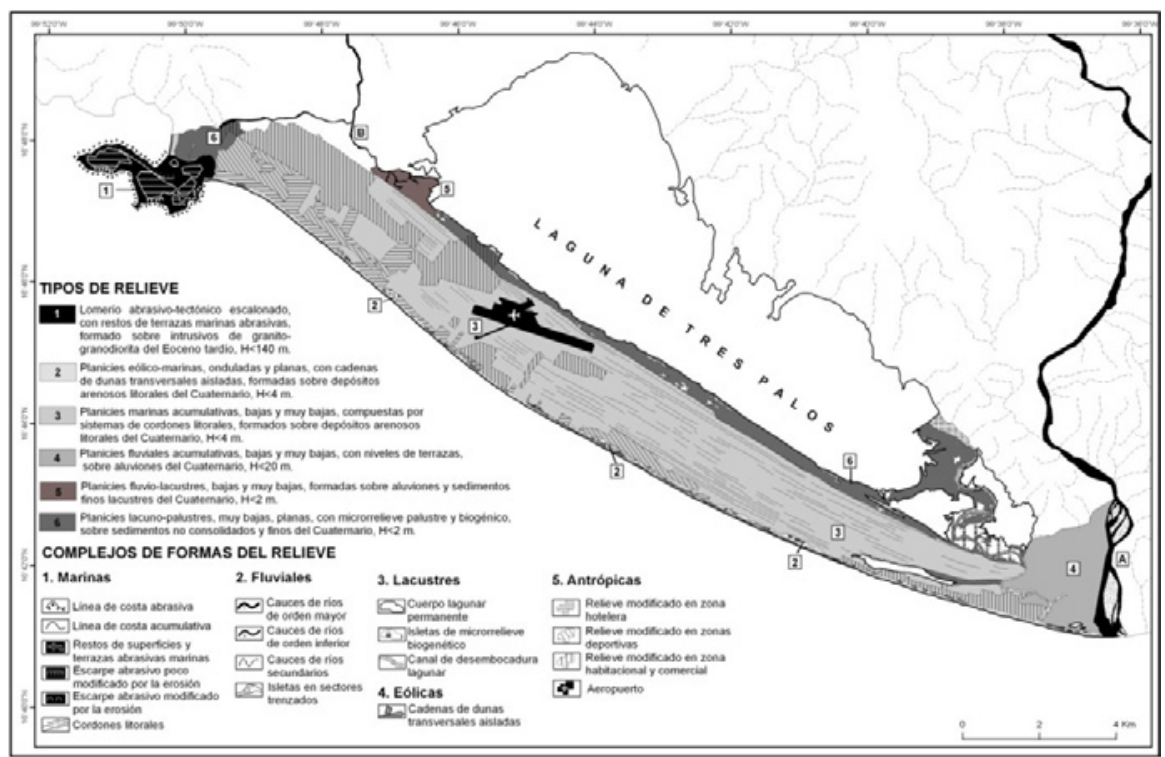

Fuente: elaboración propia.

Figura 4

PERFILES MORFOLÓGICOS EN ESTACIONES INSTRUMENTALES COSTERAS

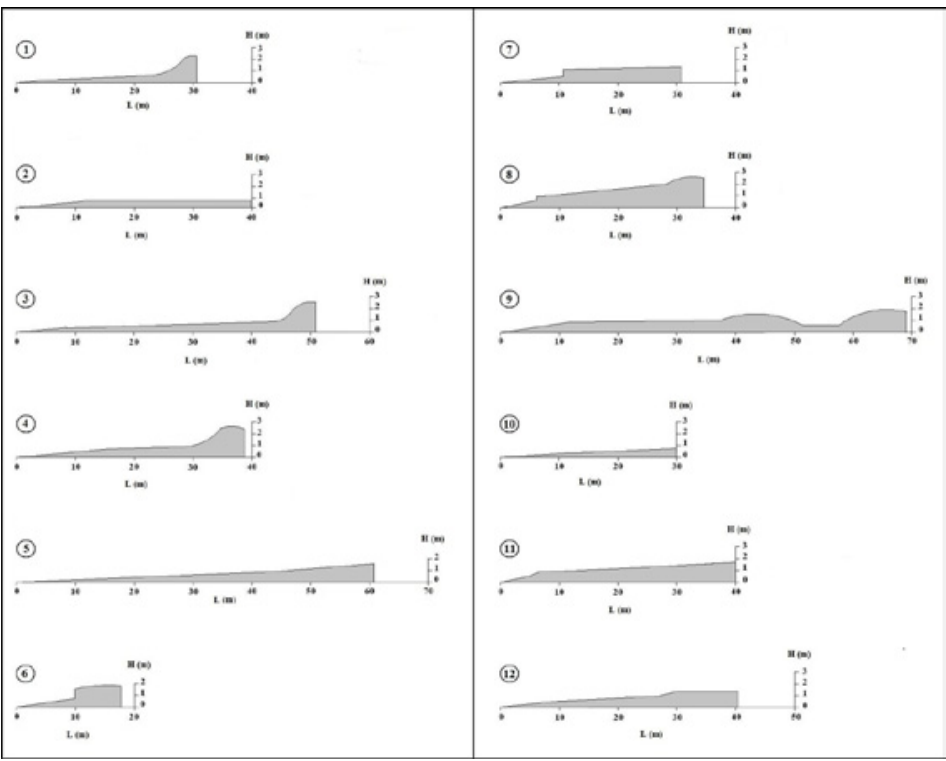

Fuente: elaboración propia. 


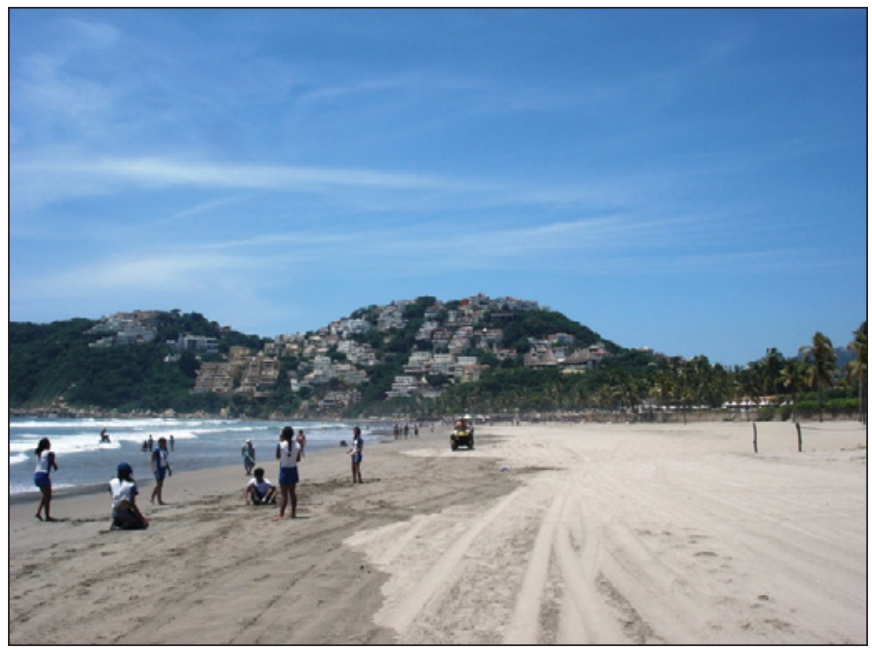

Las llanuras marinas acumulativas presentan una serie de cordones litorales, que indican el carácter progradante regional de la costa, con una fuente de sedimentos continua, que permite una evolución homogénea de la costa. La alimentación sedimentaria del litoral es favorecida por dos principales fuentes: el flujo sedimentario en la desembocadura del Río Papagayo y la alimentación de las playas por procesos abrasivos de los acantilados de los lomeríos abrasivo-tectónicos (Fig. 5).

\section{IV.2. Cambios morfodinámicos de la línea costera.}

Tras la compilación de los insumos cartográficos existentes, se trabajó con fuentes de tres diferentes marcos temporales, que son 1951, 1995 y 2007; por lo tanto, el análisis multitemporal pudo efectuarse en dos períodos de comparación, entre 1951-1995 y 1995-2007, con 44 y 12 años de comparación respectivamente.

A continuación, las tablas 1 y 2 sintetizan la información correspondiente a los diferentes tipos de atributos e incertidumbres generadas para cada año y cada período comparativo, basadas en Fletcher et al. (2003) y Ruggiero et al. (2013) respectivamente, y ajustadas a las condiciones de la zona de estudio y a los materiales de trabajo disponibles.

En términos generales, con relación a los resultados obtenidos para cada uno de los dos períodos de análisis, se encontró que para el período más antiguo, que abarca 44 años, se registró una progradación total promedio de $+74.46 \mathrm{~m}$, lo que indica un proceso de ampliación de las playas. Las tendencias de esta progradación, en gran medida, se mostraron homogéneas a lo largo de casi toda la costa, con valores que fluctúan entre los +50 y $+120 \mathrm{~m}$; sin embargo, el frente deltaico del Río Papagayo es la zona que presentó valores de movimiento neto, que alcanzaron los $+360 \mathrm{~m}$, como resultado del constante aporte sedimentario del mismo río (Figura 6). 
Tabla 1

INCERTIDUMBRE PARA CADA LÍNEA DE COSTA

\begin{tabular}{|c|c|c|c|c|}
\hline Año & $\begin{array}{c}\text { Rango de } \\
\text { Marea (m) }\end{array}$ & $\begin{array}{c}\text { Tamaño de } \\
\text { pixel }(\mathbf{m})\end{array}$ & $\begin{array}{c}\text { Error promedio de } \\
\text { digitalización en pantalla (m) }\end{array}$ & $\begin{array}{c}\text { Incertidumbre } \\
(\mathbf{m})\end{array}$ \\
\hline 1951 & 0.68 & 10 & 3 & \pm 13.68 \\
\hline 1995 & 0.68 & 2 & 3 & \pm 5.68 \\
\hline 2007 & 0.68 & 1 & 3 & \pm 4.68 \\
\hline
\end{tabular}

Fuente: elaboración propia.

Tabla 2

ATRIBUTOS E INCERTIDUMBRE PARA CADA PERIODO COMPARATIVO

\begin{tabular}{|c|c|c|c|c|}
\hline $\begin{array}{c}\text { Períodos } \\
\text { comparativos }\end{array}$ & $\begin{array}{c}\text { Número } \\
\text { de años }\end{array}$ & $\begin{array}{c}\text { Número de } \\
\text { transectos }\end{array}$ & $\begin{array}{c}\text { Nivel de } \\
\text { incertidumbre } \\
\text { total (m) }\end{array}$ & $\begin{array}{c}\text { Nivel de } \\
\text { incertidumbre } \\
\text { anual (m/año) }\end{array}$ \\
\hline $1951-1995$ & 44 & 1034 & 19.36 & 0.44 \\
\hline $1995-2007$ & 12 & 1039 & 13.00 & 0.79 \\
\hline
\end{tabular}

Fuente: elaboración propia.

Figura 6

VARIACIONES ESPACIO-TEMPORALES DE LA LINEA DE COSTA

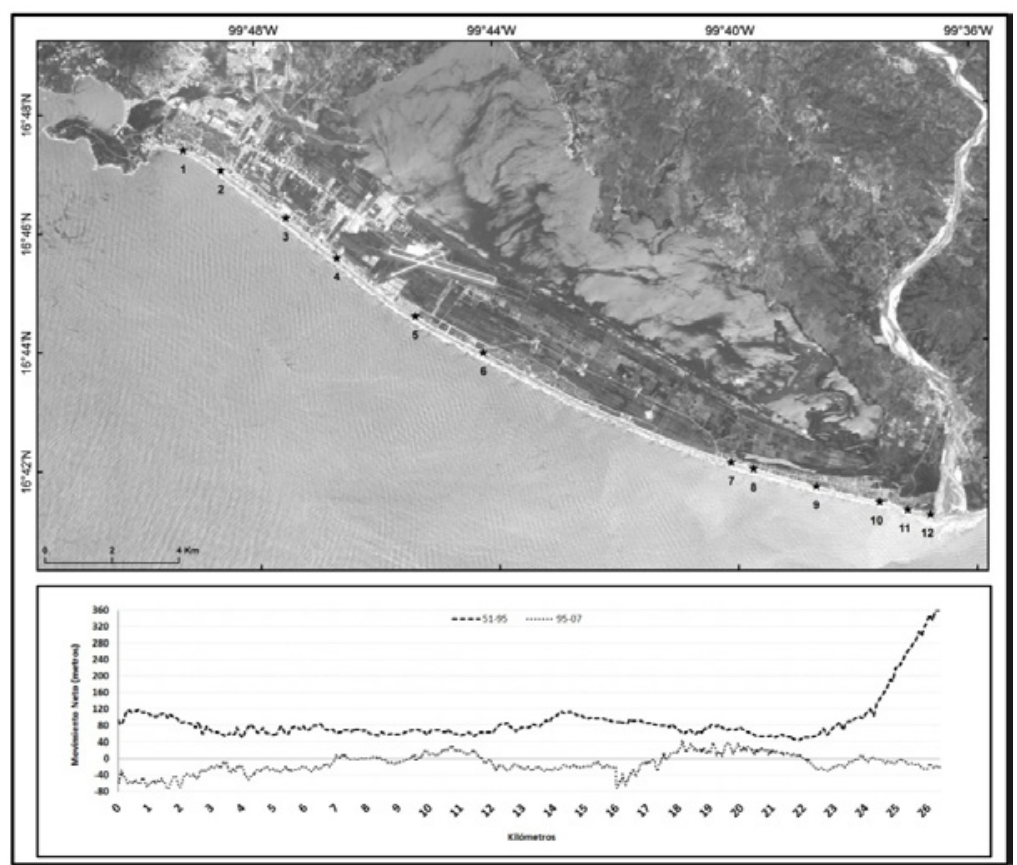

Fuente: elaboración propia; ortofoto 1:20 000 (INEGI, 1995). 
Las tasas de progradación para este primer período, se muestran dentro de un rango que va desde un valor mínimo de +1.05 hasta +7.94 m/año. Estas tasas muestran que para este primer período de análisis, la costa se mantuvo con una tasa de progradación relativamente alta y estable, con valores máximos en los extremos de la zona de estudio.

Para el período de análisis más reciente, que comprende un lapso de tiempo de 12 años (1995-2007), aproximadamente el 70\% de los transectos presentaron valores negativos de desplazamiento neto desde los -72.61 hasta los $+45.79 \mathrm{~m}$, con un valor medio de $-13.16 \mathrm{~m}$. Es importante identificar, que el valor máximo de este período se iguala al valor mínimo del primer período de análisis (Fig. 7). Las tendencias erosivas predominan en gran parte de las playas con valores máximos y críticos en la porción norte y tasas máximas de +3.7 m/año en zonas de progradación y de $-6.0 \mathrm{~m} / \mathrm{año}$ en zonas con erosión, arrojando un valor medio de $-1.06 \mathrm{~m} / \mathrm{año}$.

Dadas las condiciones diferenciales de ocupación de las playas y de modificación antrópica, producto de la expansión de las actividades humanas locales y a fin de realizar un análisis más detallado, que permitiese contrastar las diferencias de los patrones espaciales de erosión-progradación de manera puntual, se determinó la sectorización de la costa en dos sectores: (a) el sector norte-noroeste, desde Punta Diamante hasta el Club de Golf «Tres Vidas» (estaciones 1 a la 6), y (b) el sur-sureste, desde dicho campo de golf hasta la desembocadura del Río Papagayo (estaciones 7 a la 12) (Fig. 1).

Figura 7

VARIACIONES TEMPORALES DE LA LÍNEA DE COSTA
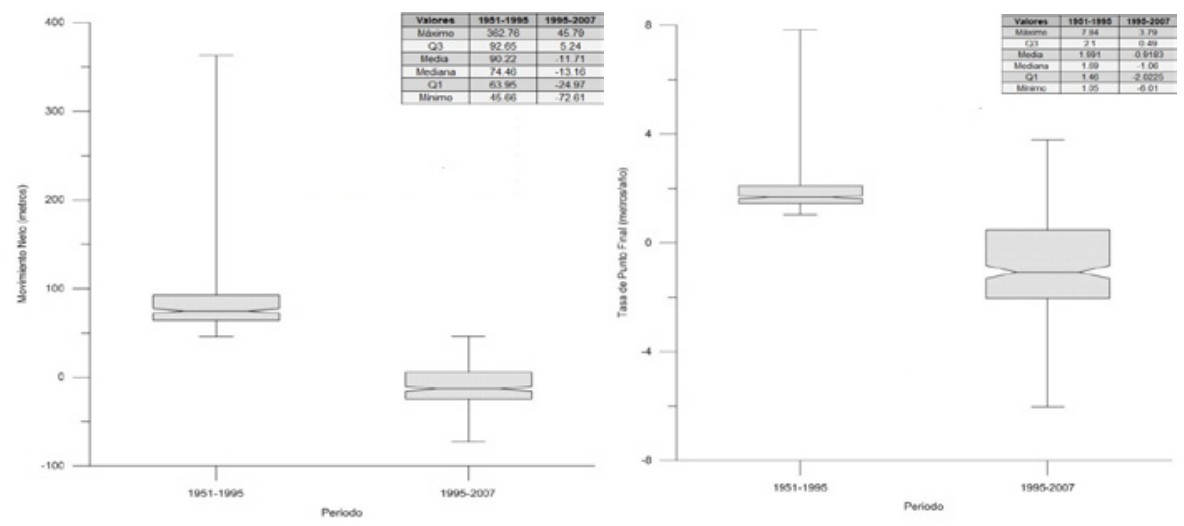

Fuente: elaboración propia.

\section{IV.2.1. Sector Norte (Playa Diamante - Campo de Golf «Tres Vidas»)}

Las playas del sector norte-noroeste presentan mayor nivel de modificación por el desarrollo urbano y turístico circundante, contando con una alta densidad de complejos hoteleros, que durante varios lustros han influido en sus rasgos morfológicos y condiciones ambientales. Esta presión de ocupación en este sector de la zona costera justifica, de cierta manera, las diferencias espacio-temporales de erosión y progradación en la línea de costa. Los valores registrados puntualmente en cada una de las estaciones de muestreo se muestran en la tabla 3 , 
así mismo las condiciones morfológicas de las playas y sus datos morfométricos de longitud y altura pueden ser vistos y comparados en la Figura 4.

Desde el punto de vista ambiental y socioeconómico, la tabla 4 presenta las características morfométricas y ambientales en los sectores de mediciones instrumentales (estaciones 1 a la 6).

En la estación 1, en «Villas del Princess», se aprecian restos de dunas parcialmente modificadas por la actividad humana, pues hacia el este-sureste la densidad hotelera y residencial han sobrepasado la capacidad de carga de la playa y alterado el paisaje costero (Fig. 8). Los valores de progradación y erosión en los períodos de análisis fueron de +110.5 m (19511995) y -66.88 m (1995-2007) respectivamente, que se traducen en tasas de +2.5 y $-5.54 \mathrm{~m} /$ año respectivamente.

Tabla 3

MORFODINÁMICA COSTERA, REGISTRADOS EN CADA ESTACIÓN DE CAMPO DEL SECTOR NORTE

\begin{tabular}{|c|c|c|c|c|}
\hline Período & \multicolumn{2}{|c|}{$\mathbf{1 9 5 1 - 1 9 9 5}$} & \multicolumn{2}{c|}{ 1995-2007 } \\
\hline $\begin{array}{c}\text { Estación de } \\
\text { campo }\end{array}$ & $\begin{array}{c}\text { Desplazamiento } \\
\text { Total }(\mathbf{m})\end{array}$ & $\begin{array}{c}\text { Tasa de } \\
\text { progradación } \\
\text { (m/año) }\end{array}$ & $\begin{array}{c}\text { Desplazamiento } \\
\text { Total }(\mathbf{m})\end{array}$ & $\begin{array}{c}\text { Tasa de erosión } \\
\text { (m/año) }\end{array}$ \\
\hline $\mathbf{1}$ & +110.59 & +2.53 & -66.88 & -5.54 \\
\hline $\mathbf{2}$ & +86.26 & +1.98 & -37.61 & -3.11 \\
\hline $\mathbf{3}$ & +65.91 & +1.51 & -26.54 & -2.20 \\
\hline $\mathbf{4}$ & +69.97 & +1.6 & -15.70 & -1.30 \\
\hline $\mathbf{5}$ & +69.77 & +1.6 & -3.38 & -0.28 \\
\hline $\mathbf{6}$ & +64.07 & +1.45 & -4.75 & -0.39 \\
\hline
\end{tabular}

Fuente: elaboración propia.

Tabla 4

CARACTERISTIICAS MORFOMÉTRICAS Y AMBIENTALES EN EL SECTOR NORTE

\begin{tabular}{|c|c|c|c|c|c|c|c|c|c|c|c|c|c|c|c|c|c|c|}
\hline \multirow{3}{*}{ PERFIL } & \multicolumn{2}{|c|}{ MORFOMETRÍA } & \multirow{2}{*}{\multicolumn{2}{|c|}{$\begin{array}{l}\text { DUNAS } \\
\text { Presencia }\end{array}$}} & \multicolumn{7}{|c|}{ VEGETACIÓN } & \multicolumn{4}{|c|}{ ASENTAMIENTOS } & \multirow{2}{*}{\multicolumn{3}{|c|}{$\begin{array}{c}\text { FLUJO ANTRÓPIC0 } \\
\begin{array}{c}\text { Vehículos motorizados y } \\
\text { personas }\end{array}\end{array}$}} \\
\hline & \multirow{2}{*}{$\begin{array}{c}\text { Altura } \\
\text { máxima } \\
(\mathrm{m})\end{array}$} & \multirow{2}{*}{$\begin{array}{c}\text { Longitud de } \\
\text { playa (m) }\end{array}$} & & & \multicolumn{3}{|c|}{ Estrato } & \multicolumn{2}{|c|}{ Densidad } & \multicolumn{2}{|c|}{ Tipo } & \multicolumn{2}{|c|}{ Tipo } & \multicolumn{2}{|c|}{ Densidad } & & & \\
\hline & & & $\mathrm{Si}$ & No & Pastizales & Arbustivo & Arbóreo & Alta & Baja & Natural & Inducida & Hoteles & Rústicos & Alta & Baja & Alto & Medio & Bajo \\
\hline 1 & 2.32 & 30.6 & $\mathrm{X}$ & --- & $X$ & --- & $X$ & --- & $X$ & -- & $X$ & $X$ & --- & $X$ & -- & $X$ & --- & -- \\
\hline 2 & 0.99 & 39.9 & $\ldots$ & $X$ & $X$ & --- & $X$ & $\ldots$ & $\mathrm{X}$ & $\ldots$ & $X$ & $X$ & --- & $X$ & -- & $x$ & --- & -- \\
\hline 3 & 2.45 & 51.1 & $\mathrm{X}$ & --- & $X$ & --- & -- & -- & $\mathrm{X}$ & $X$ & -- & $X$ & --- & $X$ & -- & $X$ & --- & -- \\
\hline 4 & 3.24 & 38.8 & $\mathrm{X}$ & --- & $X$ & --- & $X$ & $\ldots$ & $\mathrm{X}$ & $X$ & --- & $X$ & --- & $X$ & $-{ }_{-1}$ & $X$ & --- & -- \\
\hline 5 & 1.73 & 60.8 & $\ldots$ & $X$ & --- & --- & $\mathrm{X}$ & $\cdots$ & $X$ & -- & $\mathrm{X}$ & -- & $X$ & $X$ & --- & $X$ & --- &.- \\
\hline 6 & 1.7 & 10 & $\mathrm{X}$ & & $X$ & -.- & -.- & --1 & $X$ & $X$ & --. & $X$ & --- & $\ldots$ & $\mathrm{X}$ & -.- & $X$ & -- \\
\hline
\end{tabular}

Fuente: elaboración propia.

La longitud de la playa en la estación fue de $30.6 \mathrm{~m}$, con una altura máxima de $2.32 \mathrm{~m}$, alcanzada en la cima de la duna. La morfología dunar se presenta cóncava en su pendiente de barlovento y con remanentes de vegetación sobre ella, indicando tendencias erosivas. 
La estación 2, se ubicó en la playa frontal de los condominios «Marena» (Fig. 9). Sus valores registrados en el análisis de la línea costera fueron, en el primer período de $+86.26 \mathrm{~m}(+1.9$ m/año) y en el período más reciente de $-37.61 \mathrm{~m}$ (-3.11 m/año). La playa se mostró con un perfil totalmente recto con una altura máxima de $1 \mathrm{~m}$ y un ancho de perfil de $39.9 \mathrm{~m}$. Su berma se encontró muy atenuada y sin presencia de dunas, como resultado de la amplia extensión frontal de los terrenos privados. Así mismo, la modificación de sus condiciones naturales es muy severa, con vegetación nativa prácticamente nula, siendo sustituida por pasto ornamental.

\section{Figura 8}

PANORAMA DE LA URBANIZACIÓN EN LA ZONA DEL PRINCESS

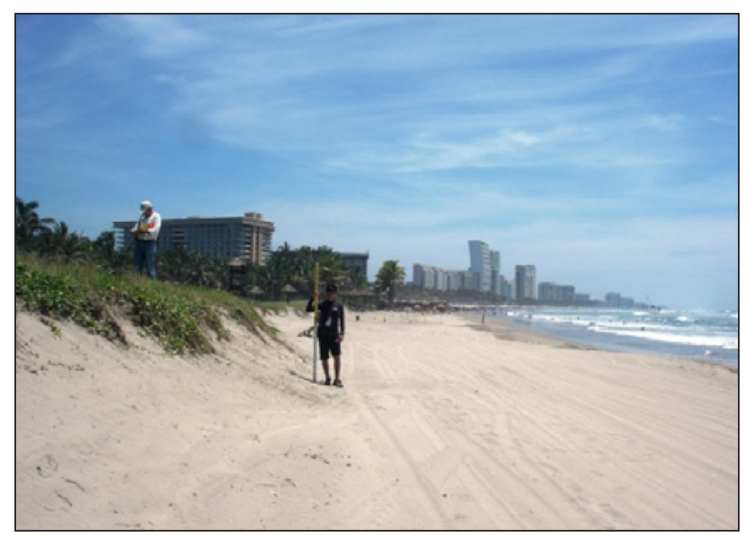

Figura 9

PERFIL DE PLAYA ESTACIÓN 2

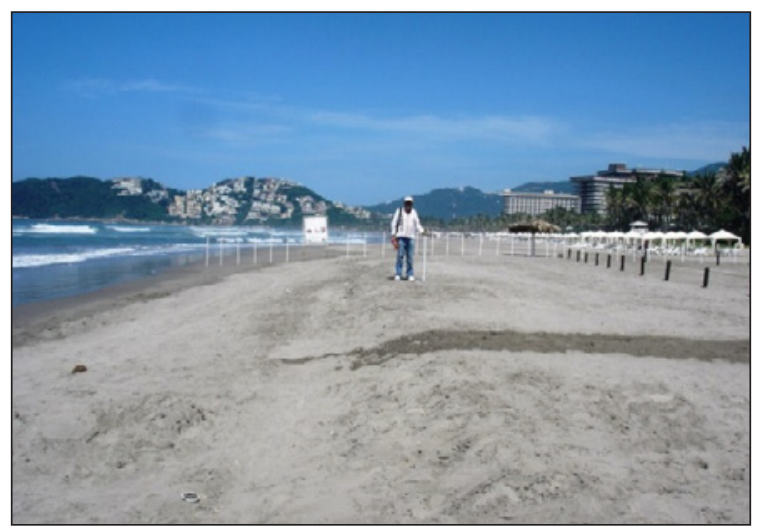

La estación 3 se estableció en el frente de un terreno privado, que no presenta construcción alguna, pero que está rodeado de edificaciones de gran tamaño (Fig. 10). En este punto, los valores históricos de progradación fueron de $+65.91 \mathrm{~m}(+1.51$ metros/año) y, en el período reciente, se registraron valores erosivos de $-26.54 \mathrm{~m}$ (-2.20 m/año). Para la 
estación 4, que de igual manera se estableció frente a un terreno con las mismas condiciones previamente mencionadas, los valores históricos son de $+69.97 \mathrm{~m}(+1.6$ metros/año) y $-15.7 \mathrm{~m}(-1.3 \mathrm{~m} / \mathrm{año})$ respectivamente.

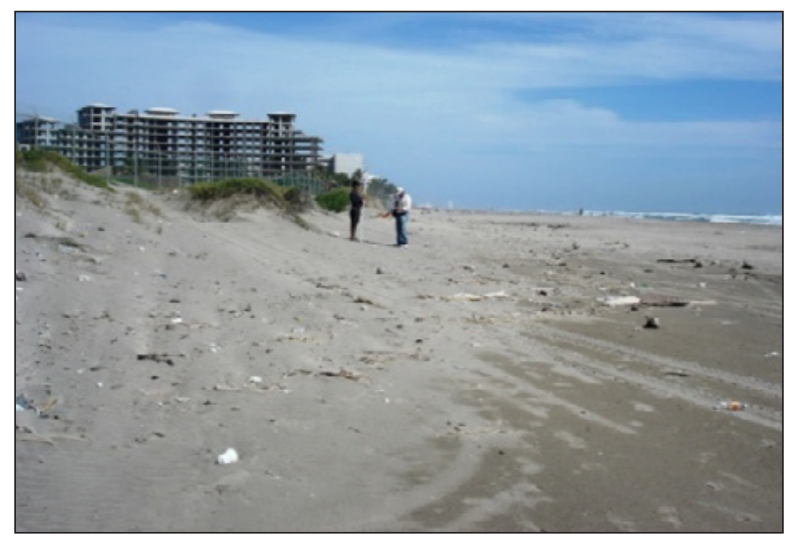

La zona aledaña a las dos estaciones arriba mencionadas, presentó algunos rasgos geomorfológicos originales, previos a la construcción de la infraestructura turística. Se detectó una berma poco desarrollada y las dunas se presentan desarrolladas, aunque tienden a estar aisladas entre sí, como resultado de su erosión. Se observan rampas erosivas entre las dunas frontales, aparentemente causadas por el paso de personas; su pendiente de barlovento es cóncava y con vegetación nativa residual en la parte superior de éstas.

La estación 5, localizada justo en el pueblo «Alfredo V. Bonfil» es una de las zonas que cuentan con los mayores cambios morfológicos y con características de exposición alta ante eventos hidrometeorológicos extremos (Fig. 11).

Los valores históricos de la dinámica de su línea costera fueron de $+69.77 \mathrm{~m}(+1.6 \mathrm{~m} /$ año) y -3.38 (-0.28 m/año). Estas tasas no reflejan totalmente la severidad del deterioro de sus playas, sin embargo, las tendencias erosivas son constantes pero disipadas por las medidas de recuperación ejercidas por los propios habitantes del poblado, quienes las retroalimentan con arena de otras zonas de la costa.

Se aprecia un perfil de playa de recto a cóncavo y sin la presencia de dunas, que fueron cubiertas por las calles que llegan prácticamente a la playa. En este sentido, la infraestructura turística se encuentra a escasos $10 \mathrm{~m}$ del límite de influencia marina directa.

Finalmente, para el sector norte se establece la estación 6, localizada entre el hotel Playa Mar y los límites del Campo de Golf «Tres Vidas». Sus respectivos valores históricos son de +64.07 m (+1.45 m/año) y -4.75 m (-0.39 m/año) para cada período analizado. Análogo a la estación 5, las modificaciones morfológicas por obras ingenieriles, asociadas con el campo de golf, han creado condiciones de inestabilidad crítica, que indiscutiblemente contribuirán a una erosión costera constante (Fig. 12), ya que cuenta con una playa bastante reducida, donde la influencia marina prácticamente altera la base del escarpe localizado al frente del campo dunar. 


\section{Figura 11}

PERFIL DE PLAYA ESTACIÓN 5

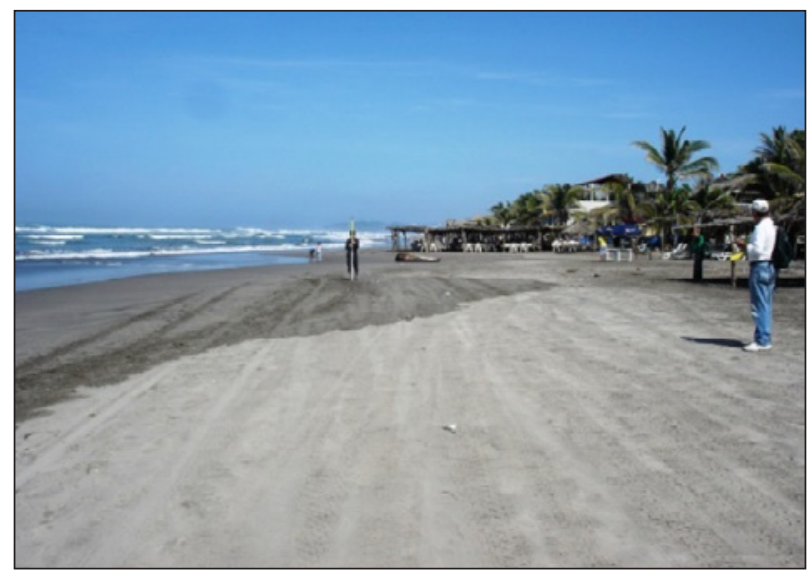

\section{IV.2.2. Sector Sur (Campo de Golf «Tres Vidas» - Desembocadura del Río Papagayo)}

Los procesos de erosión y de progradación del litoral en el sector sur están sujetos principalmente a la dinámica del aporte sedimentario del Río Papagayo, lo que determina una significativa dinámica a través del tiempo. A lo largo de este sector de costa se encuentran áreas relativamente poco pobladas, que se intercalan con algunos terrenos, aún sin construcciones, y en donde se aprecian ciertos atributos geomorfológicos menos modificados por la infraestructura urbana a gran escala. Sin embargo, estas condiciones no vuelven exenta a la zona sur de la influencia humana directa.

Figura 12

TALUD TRANSVERSAL DE LA CADENA DE DUNAS - ESTACIÓN 6

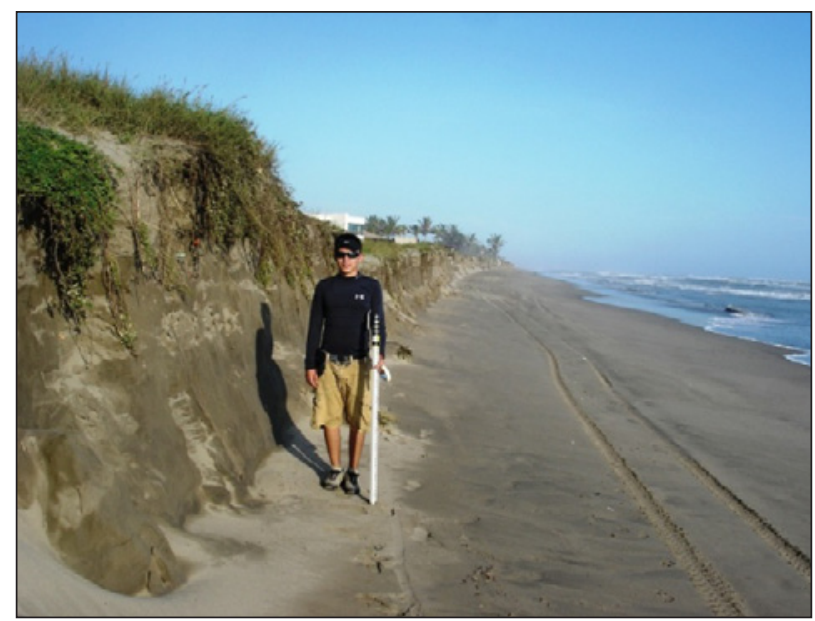


Las tendencias erosivas o acumulativas en cada una de las estaciones del sector son apreciadas en los valores de desplazamiento neto de la línea costera y sus tasas promedio por año, para cada uno de los períodos comparativos analizados, como se muestra en la Tabla 5.

Tabla 5

MORFODINÁMICA COSTERA EN CADA ESTACIÓN DEL SECTOR SUR

\begin{tabular}{|c|c|c|c|c|}
\hline Período & \multicolumn{2}{|c|}{$\mathbf{1 9 5 1 - 1 9 9 5}$} & \multicolumn{2}{c|}{ 1995-2007 } \\
\hline $\begin{array}{c}\text { Estación de } \\
\text { campo }\end{array}$ & $\begin{array}{c}\text { Desplazamiento } \\
\text { total }(\mathbf{m})\end{array}$ & $\begin{array}{c}\text { Tasa de } \\
\text { progradación } \\
\text { (m/año) }\end{array}$ & $\begin{array}{c}\text { Desplazamiento } \\
\text { total }(\mathbf{m})\end{array}$ & $\begin{array}{c}\text { Tasas } \\
(\mathbf{m} / \mathbf{a n ̃ o})\end{array}$ \\
\hline $\mathbf{7}$ & +71.47 & +1.63 & -17.96 & -1.48 \\
\hline $\mathbf{8}$ & +53.77 & +1.23 & +8.66 & +0.72 \\
\hline $\mathbf{9}$ & +66.48 & +1.50 & +25.53 & +2.11 \\
\hline $\mathbf{1 0}$ & +166.12 & +3.80 & +12.52 & +1.04 \\
\hline $\mathbf{1 1}$ & +273.88 & +6.27 & -9.80 & -0.77 \\
\hline $\mathbf{1 2}$ & +340.51 & +7.80 & -48.68 & -4.03 \\
\hline
\end{tabular}

Fuente: elaboración propia.

Desde el punto de vista ambiental y socioeconómico, la tabla 6 presenta las características morfométricas y ambientales en los sectores de mediciones instrumentales (estaciones 7 a la 12). La estación 7 se localiza aproximadamente a 8 km al sur de la estación 6 (Fig. 13). Su localización se estableció justo al frente de un terreno privado con una infraestructura rústica.

Sus valores históricos dinámicos fueron de $+71.47 \mathrm{~m}$ (+1.63 m/año) y de -17.96 m (-1.48 $\mathrm{m} / \mathrm{año}$ ). Las condiciones de interacción dinámica entre la duna y su playa adyacente son nulas, debido a la construcción realizada sobre las formas eólicas, aunado a la inserción de vegetación ornamental en algunas zonas aledañas al perfil. Por lo tanto, se observó una berma con escarpe de tormenta relativamente bien preservado y una longitud cercana a los $30 \mathrm{~m}$.

Tabla 6

CARACTERÍSTICAS MORFOMÉTRICAS Y AMBIENTALES EN EL SECTOR SUR

\begin{tabular}{|c|c|c|c|c|c|c|c|c|c|c|c|c|c|c|c|c|c|c|}
\hline \multirow{3}{*}{ PERFIL } & \multicolumn{2}{|c|}{ MORFOMETRÍA } & \multirow{2}{*}{\multicolumn{2}{|c|}{\begin{tabular}{l|} 
DUNAS \\
Presencia
\end{tabular}}} & \multicolumn{7}{|c|}{ VEGETACIÓN } & \multicolumn{4}{|c|}{ ASENTAMIENTOS } & \multirow{2}{*}{\multicolumn{3}{|c|}{$\begin{array}{c}\text { FLUJO ANTRÓPICO } \\
\begin{array}{c}\text { Vehículos motorizados y } \\
\text { personas }\end{array}\end{array}$}} \\
\hline & \multirow{2}{*}{$\begin{array}{c}\text { Altura } \\
\text { máxima } \\
(\mathrm{m})\end{array}$} & \multirow{2}{*}{$\begin{array}{c}\text { Longitud } \\
\text { de playa } \\
\text { (m) }\end{array}$} & & & \multicolumn{3}{|c|}{ Estrato } & \multicolumn{2}{|c|}{ Densidad } & \multicolumn{2}{|c|}{ Tipo } & \multicolumn{2}{|c|}{ Tipo } & \multicolumn{2}{|c|}{ Densidad } & & & \\
\hline & & & $\mathrm{Si}$ & No & Pastizales & Arbustivo & Arbóreo & Alta & Baja & Natural & Inducida & Hoteles & Rústicos & Alta & Baja & Alto & Medio & Bajo \\
\hline 7 & 1.58 & 31 &.-- & $\mathrm{X}$ & $\mathrm{X}$ & --- & $\mathrm{X}$ & -- & $\mathrm{X}$ & --- & $\mathrm{X}$ & -- & $X$ & --- & $X$ & -- & $X$ & --- \\
\hline 8 & 2.49 & 34.2 & $X$ & --- & $\mathrm{X}$ & --- & --- & --- & $X$ & $X$ & --- & --- & $\mathrm{X}$ & --- & $X$ & $X$ & -- & $\ldots$ \\
\hline 9 & 2.1 & 69.3 & $X$ & --- & $X$ & $X$ & $X$ & $\mathrm{X}$ & -- & $X$ & -- & -- & $X$ & $\ldots$ & $X$ & -- & $\mathrm{X}$ & -..- \\
\hline 10 & 0.9 & 27.4 & -- & $X$ & $X$ & & $\mathrm{X}$ & -- & $\mathrm{X}$ & -- & $\Lambda$ & -- & $\mathrm{X}$ & --- & $X$ & $X$ & -- & -- \\
\hline 11 & 1.98 & 40 & -- & $X$ & $X$ & $X$ & $X$ & X & -- & $X$ & -- & -- & -- & -.- & --- & -- & $\ldots$ & $X$ \\
\hline 12 & 1.44 & 40.5 & --. & $X$ & $X$ & $X$ & $X$ & X & ..- & $X$ & ... & -.. & -.. & ..- & ... & -..- & $\ldots$ & X \\
\hline
\end{tabular}

Fuente: elaboración propia. 


\section{Figura 13}

PERFIL DE LAESTACIÓN 7, CONASENTAMIENTOS RÚSTICOS

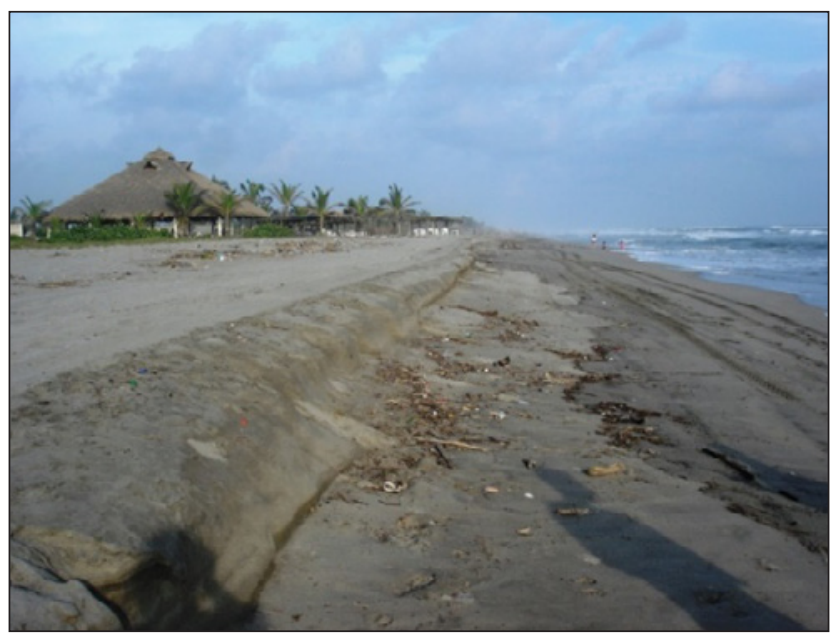

Las estaciones de muestreo 8 y 9 (Fig. 14), se pueden englobar dentro de una misma categoría de perfiles, debido a que ambas se establecieron en playas sin presencia de infraestructura urbana cercana y son las que presentan valores de estabilidad, por lo tanto, en el sector de costa al que pertenecen, prevalece la progradación de las playas (Fig. 6). Para la estación 8 , los valores históricos de progradación de su línea costera fueron de $+53.77 \mathrm{~m}(+1.23 \mathrm{~m} /$ año) y de +8.66 m (+0.72 (m/año); mientras que la estación 9 registró valores de $+66.48 \mathrm{~m}$ (+1.50 m/año) y $+25.53 \mathrm{~m}$ (+2.11 m/año) respectivamente para cada período.

Figura 14

ESTACIÓN 9, CON DUNAS BIEN PRESERVADAS Y VEGETACIÓN TÍPICA

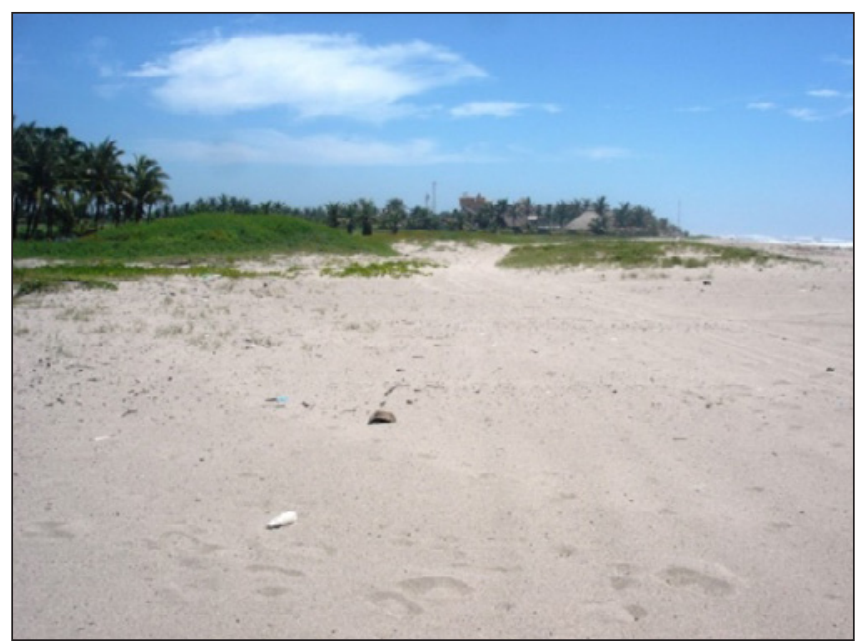


Los valores indican tendencias a la progradación costera, lo cual se puede corroborar con las condiciones ambientales y morfológicas. Inicialmente, se presentó una escasa o casi nula presencia de infraestructura urbana. Ambos perfiles mostraron una berma bien desarrollada, con un escarpe de tormenta somero. La presencia del campo dunar es un indicador importante de estabilidad, ya que a diferencia de casi todos los perfiles con dunas, su pendiente de barlovento se mantiene convexa y aún prevalece la vegetación nativa.

La estación 10 se estableció en las playas del poblado Barra Vieja, sus condiciones morfodinámicas históricas pueden considerarse estables, ya que para el período 1951-1995 se registró progradación en las playas, con un desplazamiento total de $+166 \mathrm{~m}(+3.8 \mathrm{~m} / \mathrm{año})$ y para el período 1995-2007 se obtuvo un valor de +12.5 m (+1.04 m/año).

A pesar de que las condiciones históricas se mantienen con valores positivos en las variaciones de su línea de costa, las condiciones ambientales de las playas lucen similares a las del sector norte, en donde la densidad espacial de los inmuebles es alta y se crea una barrera que interrumpe la interacción del sistema duna-playa, pese a que los asentamientos son de tipo rústico (Fig. 15), lo que muestra un perfil de playa semirrecto y sin presencia de dunas. Las condiciones de vegetación natural han sido sustituidas por vegetación de tipo ornamental.

Finalmente, las zonas de mayor erosión reciente de la costa son las áreas vecinas a las estaciones 11 y 12, vinculadas a la influencia del Río Papagayo. Inicialmente registraron valores muy altos de progradación, del orden de +273 y $+340 \mathrm{~m}$, a tasas medias anuales de +6.2 y $+7.8 \mathrm{~m} /$ año. En el período 1995-2007, los valores se invirtieron hacia tendencias erosivas con - 9.8 y - $48.68 \mathrm{~m}$, con tasas medias anuales de - 0.77 y - $4.03 \mathrm{~m} /$ año, debido a la acción erosiva de la costa por los huracanes Roxanne (1995), Paulina (1997), Wilma (2005), Dean (2007) y otros eventos hidrometeorológicos, así como por la retención sedimentaria en la hidroeléctrica «General Ambrosio Figueroa», localizada en el valle bajo del Río Papagayo. En la Figura 16, se aprecian escalones erosivos activos en condiciones de fuertes pendientes del perfil de playa, al oeste de la desembocadura de dicha corriente fluvial.

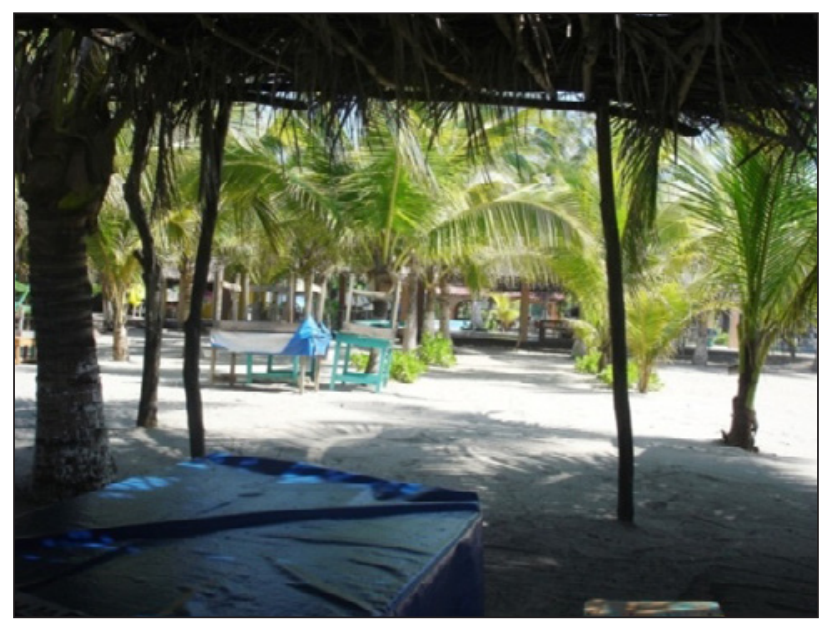




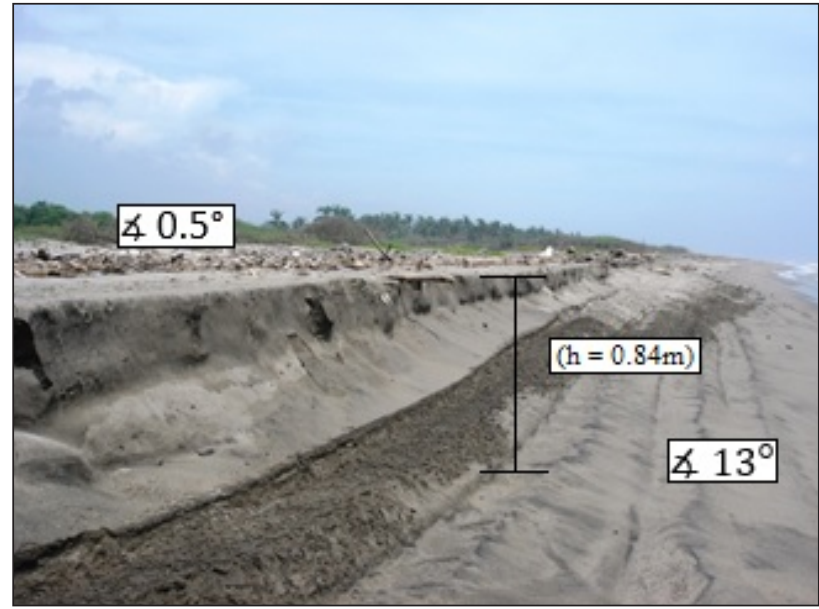

\section{CONCLUSIONES}

La ausencia de una adecuada planeación territorial y de una política real de manejo integrado de la zona costera de Acapulco Diamante ha propiciado, en términos históricos, un desarrollo turístico y urbano desorganizado y sobredimensionado, totalmente divorciado de la estructura, funcionamiento y dinámica de los procesos de los sistemas naturales circundantes. Esta falta de visión se evidencia en el deterioro de los perfiles de equilibrio de las playas, en gran parte del litoral, y en el grado de modificación antrópica de sus ecosistemas costeros.

La degradación de los paisajes naturales de la costa también se vincula al grado de urbanización desmedida, que se ha expandido a la zona contigua al litoral. En el sector norte-noroeste del área estudiada, la expansión urbana opera con mayor voracidad y rapidez, representada por grandes complejos hoteleros y zonas residenciales, mientras que en el sector sur-sureste, el tipo de asentamiento tiende a ser rústico e incluso predominan aún algunas zonas sin asentamientos humanos.

El análisis multitemporal de la morfodinámica de las playas propició conocer y cuantificar las tendencias hiperanuales de los procesos costeros de erosión y de progradación durante los últimos 56 años. La sectorización de la zona costera, en norte-noroeste y sur-sureste, permitió establecer la comparación de las variaciones morfodinámicas hiperanuales (19512007), bajo diferentes niveles de presión socioeconómica, y revelar la estrecha correspondencia existente entre las modificaciones morfológicas y ambientales de las playas, y las tendencias de erosión y/o progradación de la línea de costa.

Esto fue validado en algunos perfiles de las estaciones seleccionadas, donde los sitios con notables modificaciones en el sistema playa-duna-llanura eólico-marina cuentan, a su vez, con tendencias actuales de erosión costera. Las tendencias ambientales negativas y la erosión de las playas evidencian su carácter reciente, reflejándose las mayores pérdidas e irreversibles modificaciones en los últimos 12 años (1995-2007), coincidentes con el mayor esplendor del crecimiento urbano y turístico. 
Los resultados del análisis morfodinámico de la costa permitieron identificar tres zonas de erosión máxima:

(a) Punta Diamante: hacia el sur-sureste de la estación No. 4, las playas mostraron la mayor pérdida en años recientes, motivado por la lejanía con respecto a la principal fuente de sedimentos, el Río Papagayo, y la ampliación y explotación ilimitada de los grandes complejos hoteleros;

(b) Club de Golf «Tres Vidas»: presenta tendencias erosivas menores a Punta Diamante, pero aparentemente la influencia antrópica en la construcción de la infraestructura deportiva ha favorecido la pérdida de playas, donde sus dunas muestran un perfil totalmente modificado y expuesto a una acción erosiva activa y sostenida; y

(c) Desembocadura del Río Papagayo: presentaba una gran dinámica sedimentaria, debido a la descarga de azolves de esta notable corriente fluvial; esta zona mostró históricamente progradación significativa, que se invirtió en la última década, posiblemente como resultado de la reducción en la carga de sedimentos fluviales, debido a la existencia aguas arriba de la hidroeléctrica «General Ambrosio Figueroa», que contribuye al déficit de sedimentos por constituir una trampa para el escurrimiento sólido.

En general, las zonas con mayor erosión costera se corresponden con las playas que presentan modificaciones notables de sus condiciones morfológicas por la actividad turística, lo que ha acarreado pérdida de tierras y ha facilitado las afectaciones ante fenómenos hidrometeorológicos extremos (tormentas o ciclones tropicales, huracanes, olas de surgencia, otros), conducentes al aumento del nivel medio del mar en el corto plazo, o a mayores plazos temporales, relacionados con el cambio climático. Frente a esta realidad, es vital proteger las condiciones naturales costeras y privilegiar estas áreas para un turismo sustentable sobre bases de una óptima planeación y un adecuado manejo integrado intersectorial.

\section{AGRADECIMIENTOS}

Los autores agradecen a la Universidad Nacional Autónoma de México y, en especial, a su Instituto de Geografía, el apoyo presupuestario para las investigaciones geográficas y las mediciones instrumentales en la zona costera, así como por el financiamiento del Programa de Becas «María Teresa Gutiérrez de MacGregor». Al Ing. José Arturo Montiel Rosado (†), por las facilidades ofrecidas en el uso de las fotos aéreas del año 1985, propias de su acervo personal. A los revisores anónimos, la gratitud por sus valiosos comentarios y sus acertadas sugerencias durante el proceso de arbitraje científico.

\section{REFERENCIAS BIBLIOGRÁFICAS}

AEROFOTO (1985): «Fotografías aéreas de Acapulco a escala 1:20 000». México, D.F. AZUZ-ADEATH, I. y RIVERA-ARRIAGA, E. (2009): «Descripción de la dinámica poblacional en la zona costera mexicana durante el período 2000-2005». Papeles de Población, $\mathrm{n}^{\circ}$ 62, pp. 75-107. 
BARRAGÁN MUÑOZ, J.M. (2003): Medio ambiente y desarrollo en áreas litorales. Introducción a la planificación y gestión integradas. Universidad de Cádiz, 303 p.

BORUFF, B. ., EMRICH, C. †, CUTTER, S.L. (2005): «Erosion Hazard Vulnerability of US Coastal Counties». Journal of Coastal Research, vol. 21, No. 5, pp. 932-942.

CONAGUA (2011): Estadísticas del Agua en México. SEMARNAT, México, D. F., 181 p.

CONSEJO DE RECURSOS MINERALES (1999): Monografía geológico-minera del estado de Guerrero» Secretaría de Comercio y Fomento Industrial, México, D. F., 262 pp.

CROWELl, M., EDELMAN, S., COULTON, K. Y McAFEE, S. (2007): «How Many People Live in Coastal Areas? ». Journal of Coastal Research, vol. 23, no. 5, pp. iii-vi.

FLAMAND, C.L. (1991): Pacífico Tropical Mexicano, Cabo Corrientes a la frontera con Guatemala. Oceanografía geológica. En: De la Lanza Espino, G., comp. Oceanografía de mares mexicanos. AGT, México, D.F., 569 p.

FLETCHER, C., ROONEY, J., BARBEE, M., LIM, S. Y RICHMOND, B. (2003): «Mapping shoreline change using digital orthophotogrammetry on Maui, Hawaii». Journal of Coastal Research, SI 38, pp. 106-124.

FROEDE JR, C.R. (2006): «The impact that Hurricane Ivan (September 16, 2004) made across Dauphin Island, Alabama». Journal of Coastal Research, vol. 22, nº 3, pp. 561-573.

GARCÍA, E. (2004): «Modificaciones al sistema de clasificación climática de Köppen». $5^{\mathrm{a}}$ edición. México, D. F., 90 pp.

HERNÁNDEZ-SANTANA, J.R. Y REYES GONZÁLEZ, R. (2002): «Regeneración artificial de playas y desarrollo sostenible: Experiencias ambientales en la Playa de Varadero, Península de Hicacos, Cuba». Investigaciones Geográficas, n 49, pp. 43-56.

HERNÁNDEZ-SANTANA, J.R., ORTIZ-PÉREZ, M.A., MÉNDEZ-LINARES, A.P. Y GAMA CAMPILLO, L. (2008): «Morfodinámica de la línea de costa del estado de Tabasco, México: tendencias desde la segunda mitad del siglo XX hasta el presente». Investigaciones Geográficas, $\mathrm{n}^{\circ}$ 65, pp. 7-21.

HERNÁNDEZ-SANTANA, J.R., MÉNDEZ-LINARES, A.P., LÓPEZ-PORTILLO, J. Y PRECIADO LÓPEZ, J.C. (2015): «Coastal geomorphological cartography of Veracruz State, Mexico». Journal of Maps, v. 2015. DOI 10.1080 / 17445647.2015.1016128.

ICA (1951): «Fotografías aéreas a escala 1:30 000». México, D. F.

INEGI (1995): «Ortofotos de Acapulco a escala 1:20 000». México, D. F.

INEGI (2007): «Ortofotos de Acapulco a escala 1:10 000». México, D. F.

INEGI (2008): «Modelo Digital del Terreno LiDAR». México, D. F.

IPCC (1997): «Impactos regionales del cambio climático: evaluación de la vulnerabilidad». OMM-PNUMA, México, D. F., 16 pp. Disponible en http://www.ipcc.ch/pdf/specialreports/spm/region-sp.pdf.

IPCC (2013): Cambio Climático 2013. Resumen para responsables de políticas. Switzerland, 34 p. Disponible en https://www.ipcc.ch/report/ar5/wg1/docs/WG1AR5_SPM_brochure_es.pdf. JUANES-MARTÍ, J.L. (1996): «La erosión en las playas de Cuba». Tesis de Doctorado, Academia de Ciencias de Cuba, La Habana, 105 pp.

LINDEBOOM, H. (2002): «The Coastal zone: an ecosystem under pressure». En: Oceans 2020. Science, trends, and the challenge of sustainability (Field et al., Eds.). Island Press, Washington, D. C. 
MÁRQUEZ, A.Z., MÁRQUEZ, E., BOLÓNGARO A. Y TORRES, V. (2010): «Cambios en la línea de costa en la Rivera Maya debido a fenómenos hidrometeorológicos extremos ¿Consecuencia del cambio climático global? En: Botello, A.V., Villanueva-Fragoso, S., Gutiérrez J., y Rojas Galaviz, J. L., eds. Vulnerabilidad de las zonas costeras mexicanas ante el cambio climático. SEMARNAT-INE, UNAM-ICCMyL, Universidad Autónoma de Campeche, pp. 345-358.

MORENO CASASOLA, P., PERESBARBOSA ROJAS, E., TRAVIESO BELLO Y A.C. (2005). «Manejo costero integral: el enfoque municipal». Instituto de Ecología, A. C., Xalapa, $1266 \mathrm{p}$.

MORTON, R. A., MILLER, T. Y MOORE, L. (2005): «Historical Shoreline Changes along the US Gulf of Mexico: A Summary of Recent Shoreline Comparisons and Analyses». Journal of Coastal Research, vol. 21, no 4, pp. 704-709.

ORTIZ-PÉREZ, M.A. y MÉNDEZ-LINARES, A.P. (2000): «Componentes naturales y de uso del suelo vulnerables a las variaciones del nivel del mar en la costa Atlántica de México». Investigaciones Geográficas, nº 41, pp. 46-61.

PACHECO SANDOVAL, P. (1991): «Pacífico Tropical Mexicano, Cabo Corrientes a la frontera con Guatemala. Oceanografía física». En: De la Lanza Espino, G., comp. Oceanografía de mares mexicanos. AGT, México, D. F., 569 pp.

RUGGiERO, P., KRATZMANN, M., HIMMELSTOSS, E., REID, D., ALLAN, J. y KAMINSKY, G. (2013): National Assessment of Shoreline Change: Historical Shoreline Change Along the Pacific Northwest Coast. U.S. Department of the Interior and U.S. Geological Survey. Open File Report 2007-2012, 61 pp.

SEPLAP (1985): «Geografía física del estado de Guerrero». Gobierno de Guerrero, México, $155 \mathrm{p}$.

SERVICIO GEOLÓGICO MEXICANO (2000): «Carta geológico-minera Acapulco e14-11, Guerrero y Oaxaca, escala 1:250,000» México, D.F.

SERVICIO METEOROLÓGICO NACIONAL (SMN) (2013): «Datos de planos de marea de la estación Acapulco, Guerrero». Disponible en http://www.mareografico.unam.mx/ Mareografico.

THIELER, E. R., HIMMELSTOSS, E. A., ZICHICHI, J. J. y MILLER, T.L. (2005): Digital Shoreline Analysis System (DSAS) version 3.0; An ArcGIS extension for calculating shoreline change: US Geological Survey Open-File Report 2005-1304.

THOMAS-BOHÓRQUEZ, J.E. (2013): «Evaluación de la vulnerabilidad social ante amenazas naturales en Manzanillo (Colima). Un aporte de método». Investigaciones Geográficas, $\mathrm{n}^{\circ} 81$, pp. 79-93.

VÁZQUEZ DOMÍNGUEZ, E., ARRIAGA, L., GONZÁlEZ CANO, J., AGUILAR, V., OLVERA, R. M., BERALDI, H. Y ALARCÓN J. (1998): «La regionalización. Provincias costeras y oceánicas». En: Arriaga Cabrera, L., Vázquez Domínguez, E., González Cano, J., Jiménez Rosenberg, R., Muñoz López, E., Aguilar Sierra, V., Coords. Regiones prioritarias marinas de México. CONABIO, México, D. F., 198 pp. 